\title{
The association of ectonucleotide pyrophosphatase/ phosphodiesterase 1 (ENPP1) K121Q gene polymorphism with the risk of type 2 diabetes mellitus in European, American, and African populations: A meta-analysis
}

\author{
Jonny Karunia Fajar
}

Medical Research Unit, School of Medicine, University of Syiah Kuala, Banda Aceh, Indonesia

\begin{abstract}
Introduction: Several studies regarding the association of the ectonucleotide pyrophosphatase/phosphodiesterase 1 (ENPP1) K121Q gene polymorphism with the risk of type 2 diabetes mellitus (T2DM) showed inconsistent results. This study aimed to investigate the association of ENPP1 K121Q gene polymorphism with T2DM risk using meta-analysis. The study was limited to the American, European, and African populations.

Methods: PubMed and Embase databases were searched for eligible publications. The following information was extracted from each study: Name of first author, publication year, country of origin, sample size of cases and controls, and size of each allele. The combined odds ratios (ORs) and 95\% confidence intervals (95\% Cls) for the association between ENPP1 K121Q gene polymorphism and T2DM risk were assessed using random or fixed effect model. A comprehensive meta-analysis (CMA) 2.0 was used to analyze the data.

Results: Nineteen studies (17717 cases/28022 controls) on the association between ENPP1 K121Q gene polymorphism and T2DM risk were included in this meta-analysis. The results indicated that the ENPP1 K121Q gene polymorphism was associated with increased T2DM risk (Q vs. K genetic model, OR 95\% $\mathrm{Cl}=1.11$ [1.02-1.22], $p=0.014 ; \mathrm{QQ}$ vs. $\mathrm{KK}+\mathrm{KQ}, \mathrm{OR} 95 \% \mathrm{Cl}=1.14$ [1.01-1.23], $p=0.039)$ and decreased T2DM risk (K vs. Q, OR 95\% Cl=0.90 [0.82-1.00], $p=0.014 ; \mathrm{KK}$ vs. $\mathrm{KQ}+\mathrm{QQ}, \mathrm{OR} 95 \% \mathrm{Cl}=$ 0.89 [0.80-0.98], $p=0.024$ ).
\end{abstract}

Conclusions: The results indicate that the ENPP1 $\mathrm{K} 121 \mathrm{Q}$ gene polymorphism is associated with the risk of T2DM in the American, European, and African populations.

Keywords: ENPP1 K121Q gene polymorphism; type 2 diabetes mellitus; genetic polymorphism; meta-analysis; insulin resistance.INTRODUCTION

Corresponding author: Jonny Karunia Fajar, Medical Research Unit, School of Medicine, University of Syiah Kuala, Jl. Tanoeh Abe, Darussalam, Banda Aceh 23111, Indonesia, Tel.: +62(0)81235522287, Fax: +62(0)651 7551843, 


\section{INTRODUCTION}

Type 2 diabetes mellitus (T2DM) is the most common form of diabetes worldwide (1), and includes a complex group of chronic metabolic disorders characterized by hyperglycemia. This is the result of two distinct pathophysiological states: a) defects in insulin secretion caused by impaired pancreatic $\beta$-cell function and b) disruption of insulin action caused by insulin resistance in muscle, fat, and the liver (2-4). T2DM is multifactorial in origin with both genetic and environmental factors contributing to its development. The prevalence of T2DM has increased over time. T2DM affected approximately $4 \%$ of the world's adult population (1). The World Health Organization (5) estimated that the prevalence and number of people with diabetes in 2014 was 25 million in African, 62 million in American, and 64 million in European population. While DeFronzo (2) reported that approximately 15.6 million persons have T2DM, and about 13.4 million have impaired glucose tolerance in the United States (US), a study by Wild et al. (6) reported that the prevalence of diabetes for all age groups worldwide was estimated to be $2.8 \%$ in 2000 and $4.4 \%$ in 2030 year. The mortality number caused by T2DM has also increased. The total burden of deaths from high blood glucose1 in 2012 was estimated to be 3.7 million. This number includes 1.5 million diabetes deaths and an additional 2.2 million deaths from cardiovascular diseases, chronic kidney disease, and tuberculosis related to higher-than-optimal blood glucose. The largest number of deaths resulting from high blood glucose occurs in upper-middle income countries (1.5 million) and the lowest number in low-income countries ( 0.3 million). The mortality rate per 100000 population was 111.3 in African, 72.6 in American, and 55.7 in European population. The total annual expenditure for T2DM has been increasing. Based on the cost estimates, direct annual cost of diabetes to the world is more than US\$ 827 billion (5). T2DM is a complex disorder resulting from an interaction between genes and environment (7). Recently, ectonucleotide pyrophosphatase/phosphodiesterase 1 (ENPP1) gene variants have been identified to have a significant functional role in determining susceptibility to T2DM (8).

ENPP1, also known as plasma cell alloantigen 1 (PC1), is an enzyme involved primarily in hydrolysis of ATP at the cell surface (9). The enzyme is highly expressed in adipocytes and is also found in other tissues involved in glucose and lipid metabolism, including liver, skeletal muscle, and $\beta$-cells of the pancreas (10). ENPP1 is a transmembrane glycoprotein that down-regulates insulin signaling in cells by inhibiting the tyrosine kinase activity of the insulin receptor (IR), perhaps by interaction with its $\alpha$-subunit (11). The ENPP1 is a promising candidate gene for T2DM because it inhibits autophosphorylation of IR and impairs insulin signaling downstream of IR (12). A study found that the 121Q variant had a greater inhibitory action on IR compared to the $121 \mathrm{~K}$ variant (13).

Several polymorphism studies have shown the association between the ENPP1 K121Q gene polymorphism and the risk of T2DM, however the results were inconsistent. Studies conducted by Rasmussen et al. (14), Abate et al. (15), Meyre et al. (16), Chandalia et al. (17), Willer et al. (18), Bouhaha et al. (19), and Leitao et al. (20) showed that the ENPP1 K121Q gene polymorphism was associated with increased risk of T2DM. Whereas several other studies (21-32) showed that the ENPP1 K121Q gene polymorphism had no significant association with increased risk of T2DM. A meta-analysis study is required to determine the actual association of the above-mentioned studies.

This study aimed to investigate the association between the ENPP1 K121Q gene polymorphism and the risk of T2DM using meta-analysis. The results of this study are expected to be useful for the future treatment and prevention of T2DM. Besides, the study is also expected to be useful as a comparison to other studies on the ENPP1 K121Q gene polymorphism and T2DM.

\section{METHODS}

\section{Study designs}

A meta-analysis was conducted to assess the association of the ENPP1 K121Q gene polymorphism with the risk of T2DM. To achieve this goal, several studies regarding the association between the ENPP1 K121Q gene polymorphism and the risk of T2DM were collected for calculating combined odds ratio (OR) 95\% confidence interval (CI) and 
assessed using fixed or random effect model. Article search was conducted in Pubmed and Embase. The study was conducted from January to May, 2016.

\section{Study procedures}

The procedures of this study were (1) to identify potentially relevant studies through Pubmed and Embase database search, up to April 20 ${ }^{\text {th }}, 2016$, (2) to determine eligibility of the study; the exclusion was performed using several steps, i.e.: (a) by reading the title and abstract, (b) study designs complied with the inclusion criteria, (c) study provided sufficient data to calculate OR 95\% CI, (3) collecting abstract and full text data from the studies, (4) collecting the data for calculating OR 95\% CI, and (4) analyzing data statistically.

\section{Eligibility criteria and data extraction}

The eligibility criteria consisted of predefined inclusion and exclusion criteria. Studies were included in the analysis if they met the following inclusion criteria: (1) case-control; (2) cohort; (3) cross-sectional studies; (4) randomized-controlled trials (RCTs); (5) controlled before-and-after studies; (6) cross-over studies; (7) evaluating the associations of the ENPP1 K121Q gene polymorphism with the risk of T2DM; and (8) providing sufficient data for calculation of OR 95\% CI. Required data were extracted from each study for calculating OR 95\% CI. In addition, the following information was extracted from each study: (1) name of first author; (2) year of publication; (3) country of origin; (4) sample size of cases and controls, (5) size of each allele.

\section{Search strategy and literature}

PubMed and Embase were searched with no language restrictions, using specified search terms to identify studies published up to April $20^{\text {th }}, 2016$. The search strategy involved the use of combination of the following key words: (ENPP1 K121Q gene or ectonucleotide pyrophosphatase/phosphodiesterase $1 \mathrm{~K} 121 \mathrm{Q}$ gene) and (variant or variation or polymorphism) and (T2DM or type 2 diabetes mellitus). The publication languages were restricted to English. The reference lists of retrieved articles were hand searched. If more than one article was published using the same study data, only the study with the largest sample size was included. We used a scoring system to evaluate the quality of the studies. We used a quality assessment score modified from previous meta-analysis for observational studies. Total scores ranged from 0 (worst) to 9 (best). A study was considered low quality if scores were $<6$, and high quality if scores were $\geq 6$ (33).

\section{Study variables}

\section{ENPP1 K121Q gene}

ENPP1 is a transmembrane glycoprotein that down-regulates insulin signaling in cells by inhibiting the tyrosine kinase activity of the insulin receptor (11). The measurement results of this variable were each allele in ENPP1 K121Q gene including dominant $(\mathrm{K})$, recessive $(\mathrm{Q})$, dominant homozygous $(\mathrm{KK})$, recessive homozygous (QQ), and heterozygous (KQ). Data were obtained by searching strategy. Nominal scale was used to assess this variable.

\section{Risk of $T 2 D M$}

T2DM is a complex group of chronic metabolic disorders characterized by two distinct pathophysiological states: a) defects in insulin secretion caused by impaired pancreatic $\beta$-cell function and b) disruption of insulin action caused by insulin resistance in muscle, fat, and the liver (2-4). The measurement results of this variable were increased or decreased risk of T2DM. The data were obtained by searching strategy. Nominal scale was used to assess this variable.

\section{Statistical analysis}

The correlation of the ENPP1 K121Q gene polymorphism with the risk of T2DM was estimated by calculating pooled ORs and 95\% CI. The significance of pooled ORs was determined by $\mathrm{Z}$ tests ( $p<0.05$ was considered statistically significant). A Q test was performed to evaluate whether the heterogeneity existed. Random effect model was used to calculate OR 95\% CI if heterogeneity existed $(p<0.10)$. Fixed effect model was used to calculate OR 95\% CI if no heterogeneity existed. Publication bias was assessed by Egger's test $(p<0.05$ was considered statistically significant). Subgroup analyses based on the continent (Europe, America, 
and Africa) and sample size (small $<400$, large $\geq 400$ samples) were also performed. A comprehensive meta-analysis (CMA) 2.0 was used to analyze the data.

\section{RESULTS}

\section{Characteristics of the studies}

A total of 72 potentially relevant papers were identified based on the search strategy. Among these, 24 papers were excluded because of obvious irrelevance by reading their titles and abstracts. After the full texts were read, 20 papers were excluded because the population was not American, European, or African; three papers were excluded because they did not provide sufficient data for calculating OR with 95\% CI. In addition, six reviews were excluded. A flow chart demonstrating the inclusion or exclusion of the studies is displayed as Figure 1. A total of 19 studies were included in the meta-analysis. Twelve studies included European, four studies included American, and three studies included African population. Table 1 describes the characteristics of the studies included in the meta-analysis.

\section{Quantitative data synthesis}

A total of 17717 cases and 28022 controls were identified. Overall, the results showed that $\mathrm{K}$ vs. Q, KK vs. KQ + QQ, Q vs. K, and QQ vs. KK $+\mathrm{KQ}$ genetic models had significant association with the risk of T2DM. While, KQ vs. KK + QQ genetic model had no significant association with the risk of T2DM. The results indicated that the ENPP1 K121Q gene polymorphism was associated with increased risk (Q vs. K, OR 95\% CI $=1.11$ [1.02-1.22], $p=0.014$; QQ vs. KK + KQ, OR 95\% $\mathrm{CI}=1.14[1.01-1.23], p=0.039)$ and decreased risk of T2DM (K vs. Q, OR 95\% CI = $0.90[0.82$ $1.00], p=0.014$; KK vs. KQ + QQ, OR 95\% CI = 0.89 [0.80-0.98], $p=0.024$ ). Forest plot regarding the correlation of ENPP1 K121Q gene polymorphism with T2DM is described in Figure 2 for $\mathrm{K}$ vs. Q genetic model. Summary ORs and 95\% CIs regarding the correlation of ENPP1 K121Q gene

TABLE 1. Characteristics of studies included in the meta-analysis

\begin{tabular}{|c|c|c|c|c|c|c|c|c|c|c|c|c|}
\hline \multirow[t]{2}{*}{ Author \& Year } & \multirow[t]{2}{*}{ Country } & \multirow[t]{2}{*}{ Age (years $\pm S D$ ) } & \multirow[t]{2}{*}{ Continent } & \multirow[t]{2}{*}{ SS } & \multicolumn{2}{|c|}{ NS } & \multicolumn{3}{|c|}{ T2DM genotype } & \multicolumn{3}{|c|}{ Cont genotype } \\
\hline & & & & & T2DM & Cont & KK & $\mathrm{KQ}$ & $\mathrm{QQ}$ & $\mathrm{KK}$ & $\mathrm{KQ}$ & $Q Q$ \\
\hline Pizzuti et al. 1999 & Italy & $37.4 \pm 13.0$ & Europe & $S$ & 132 & 121 & 81 & 47 & 4 & 80 & 39 & 2 \\
\hline Gu et al. 2000 & Italy & $54.5 \pm 14.1$ & Europe & L & 392 & 147 & 304 & 80 & 8 & 110 & 36 & 1 \\
\hline Rasmussen et al. 2000 & Denmark & $8 \pm 8.8$ & Europe & $\mathrm{L}$ & 226 & 356 & 147 & 70 & 9 & 263 & 86 & 7 \\
\hline Barroso et al. 2003 & England & $63.5 \pm 0.5$ & Europe & L & 97 & 392 & 70 & 25 & 2 & 302 & 83 & 7 \\
\hline Kubaszek et al. 2004 & Finland & $.7 \pm 2.8$ & Europe & $S$ & 165 & 98 & 143 & 22 & 0 & 85 & 12 & 1 \\
\hline Abate et al. 2005 & USA & $47.6 \pm 11.7$ & America & L & 485 & 2099 & 301 & 163 & 21 & 1484 & 561 & 54 \\
\hline Meyre et al. 2005 & Austria & $40.4 \pm 8.7$ & Europe & L & 1308 & 900 & 918 & 349 & 41 & 665 & 220 & 15 \\
\hline Bacci & Italy & & Eur & L & 2270 & 1130 & 1793 & 448 & 29 & 884 & 229 & 17 \\
\hline Grarup et al. 2006 & Denmark & $45.9 \pm 8.1$ & Europe & L & 1386 & 4770 & 1037 & 316 & 33 & 3577 & 1097 & 96 \\
\hline Bochenski et al. 2006 & Poland & $54.2 \pm 12.1$ & Europe & L & 1386 & 4770 & 1037 & 316 & 33 & 3577 & 1097 & 96 \\
\hline Lyon et al. 2006 & USA & $59.1 \pm 9.7$ & America & L & 4204 & 4227 & 3094 & 1032 & 78 & 3079 & 1062 & 86 \\
\hline Weedon et al. 2006 & England & $41.0 \pm 9.2$ & Europe & L & 2287 & 3846 & 1691 & 554 & 42 & 2842 & 949 & 55 \\
\hline Chandalia et al. 2007 & USA & $43.1 \pm 8.0$ & America & L & 116 & 967 & 58 & 54 & 4 & 731 & 216 & 20 \\
\hline Willer et al. 2007 & Finland & $63.9 \pm 9.8$ & Europe & $\mathrm{L}$ & 1155 & 971 & 853 & 268 & 34 & 755 & 193 & 23 \\
\hline Meyre et al. 2007 & France & $47.0 \pm 9.0$ & Europe & L & 316 & 2005 & 223 & 79 & 14 & 1438 & 511 & 56 \\
\hline Bouhaha et al. 2008 & Tunisia & $52.2 \pm 9.6$ & Africa & $S$ & 110 & 243 & 32 & 61 & 17 & 106 & 103 & 34 \\
\hline Leitao et al. 2008 & Brazil & $56.9 \pm 10.0$ & America & L & 1027 & 240 & 571 & 371 & 85 & 111 & 102 & 27 \\
\hline El-Achhab et al. 2009 & Morocco & $44.5 \pm 9.7$ & Africa & $\mathrm{L}$ & 503 & 412 & 194 & 240 & 69 & 168 & 183 & 61 \\
\hline Yako et al. 2015 & South Africa & $56.5 \pm 12.6$ & Africa & $\mathrm{L}$ & 152 & 328 & 41 & 73 & 38 & 81 & 175 & 72 \\
\hline
\end{tabular}

USA: United States of America, SS: Sample size, L: Large ( $\geq 400$ samples), S: Small (< 400 samples), NS: Number of samples, T2DM: Type 2 diabetes mellitus, Cont: Control 


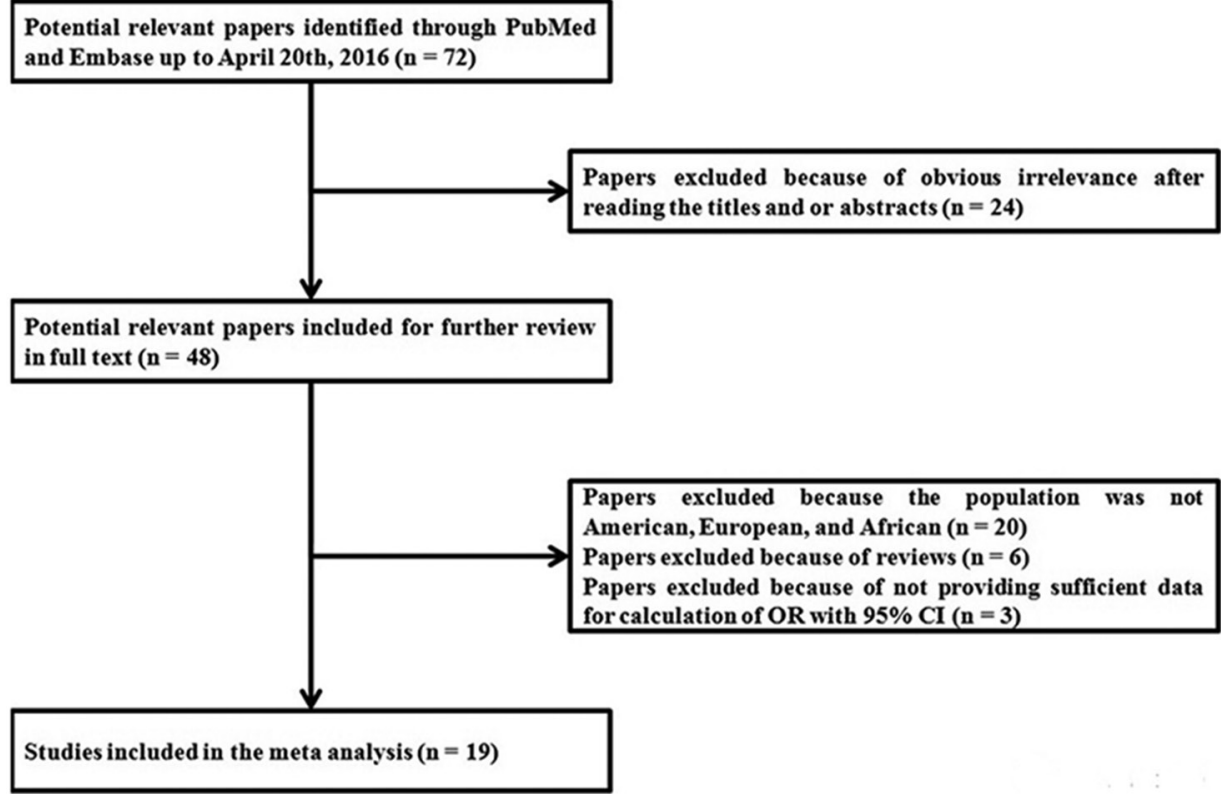

FIGURE 1. Selection of articles for inclusion in the meta-analysis

\begin{tabular}{|c|c|c|c|c|c|c|c|c|c|c|c|c|}
\hline \multirow[t]{2}{*}{ Model } & \multirow[t]{2}{*}{ Study name } & \multicolumn{5}{|c|}{ Statistics for each study } & \multicolumn{5}{|c|}{ Odds ratio and $95 \% \mathrm{Cl}$} & \multirow{2}{*}{$\begin{array}{l}\text { Weight } \\
\text { [Random] } \\
\text { Relative } \\
\text { weight }\end{array}$} \\
\hline & & Odds ratio & Lower limit & Upper limit & ZValue & p.Value & 0.01 & 0.10 & 1.00 & 10,00 & 100,00 & \\
\hline & Pizzuti et al 1999 & 0.821 & 0,527 & 1,280 & $.0,871$ & 0,384 & & & $\rightarrow$ & & & 2,68 \\
\hline & Gu et al 2000 & 1.064 & 0.712 & 1,590 & 0,301 & 0.763 & & & -1 & & & 3.05 \\
\hline & Rasmussen et al 2000 & 0.676 & 0.494 & 0.926 & $.2,442$ & 0.015 & & & + & & & 4,07 \\
\hline & Barroso et al 2003 & 0.803 & 0.513 & 1.258 & $.0,957$ & 0.338 & & & $\rightarrow$ & & & 2,64 \\
\hline & Kubaszek et al 2004 & 1,077 & 0,538 & 2,157 & 0.209 & 0.834 & & & $\longrightarrow$ & & & 1.34 \\
\hline & Abate et al 2005 & 0.707 & 0.594 & 0.843 & $.3,879$ & 0,000 & & & + & & & 6.41 \\
\hline & Meyre et al 2005 & 0.818 & 0.691 & 0.968 & $.2,336$ & 0.019 & & & + & & & 6.52 \\
\hline & Bacci et al 2005 & 1,050 & 0,896 & 1,230 & 0,603 & 0,546 & & & & & & 6,72 \\
\hline & Grarup et al 2006 & 0.977 & 0,864 & 1,105 & $.0,364$ & 0.716 & & & - & & & 7,36 \\
\hline & Bochenski et al 2006 & 0.977 & 0,864 & 1.105 & $.0,364$ & 0.716 & & & 1 & & & 7,36 \\
\hline & Lyon et al 2006 & 1.039 & 0.953 & 1,132 & 0.865 & 0,387 & & & & & & 795 \\
\hline & Weedon et al 2006 & 0.985 & 0,886 & 1.095 & $.0,281$ & 0,779 & & & & & & 7.65 \\
\hline & Chandalia et al 2007 & 0.418 & 0,304 & 0.576 & $.5,352$ & 0,000 & & & $\leftarrow$ & & & 4,01 \\
\hline & Willer et al 2007 & 0.825 & 0.690 & 0985 & $.2,124$ & 0,034 & & & + & & & 6,35 \\
\hline & Meyre et al 2007 & 0.903 & 0,721 & 1.130 & $.0,895$ & 0.371 & & & + & & & 5.49 \\
\hline & Bouhaha et al 2008 & 0.714 & 0,516 & 0.989 & $.2,027$ & 0,043 & & & + & & & 3.93 \\
\hline & Leitao et al 2008 & 1,347 & 1,086 & 1.669 & 2,715 & 0.007 & & & + & & & 5,67 \\
\hline & El-Achhob et al 2009 & 0.976 & 0.807 & 1,181 & $.0,246$ & 0.805 & & & & & & 6.11 \\
\hline & Yako et al 2015 & 0.985 & 0.750 & 1.293 & $.0,111$ & 0.912 & & & + & & & 4.70 \\
\hline Random & & 0.897 & 0,822 & 0.979 & $-2,445$ & 0,014 & & & + & & & \\
\hline
\end{tabular}

FIGURE 2. Meta-analysis of the association between the ENPP1 K121Q gene polymorphism and the risk of T2DM (K vs. Q allele)

polymorphism and T2DM are described in Table 2. In the subgroup analysis, the ENPP1 K121Q gene polymorphism was associated with the risk of T2DM in three genetic models of the Europe continent subgroup ( $\mathrm{K}$ vs. $\mathrm{Q} p=0.019$; $\mathrm{Q}$ vs. $\mathrm{K} p=$ 0.019; $Q Q$ vs. $K K+K Q p=0.005)$, in two genetic models of the small sample subgroup (KK vs. KQ+ $\mathrm{QQ} p=0.029 ; \mathrm{KQ}$ vs. KK $+\mathrm{QQ} p=0.045)$, and in three genetic models of the large sample subgroup ( $\mathrm{K}$ vs. $\mathrm{Q} p=0.033$; $\mathrm{Q}$ vs. $\mathrm{K} p=0.033$; $\mathrm{QQ}$ vs. $\mathrm{KK}+\mathrm{KQ} p=0.043)$. However, the ENPP1 K121Q gene polymorphism had no significant association with the risk of T2DM in two genetic models of the Europe continent subgroup (KK vs. KQ + QQ $p=0.095 ; \mathrm{KQ}$ vs. $\mathrm{KK}+\mathrm{QQ} p=0.453)$, all genetic models of the America continent subgroup (K vs. 
TABLE 2. Summary ORs and $95 \% \mathrm{Cls}$ of the association between the ENPP1 K121Q gene polymorphism and the risk of T2DM

\begin{tabular}{|c|c|c|c|c|c|c|c|c|}
\hline \multirow[t]{2}{*}{ No. } & \multirow[t]{2}{*}{ Alleles } & \multirow[t]{2}{*}{ Parameter } & \multirow[t]{2}{*}{ All } & \multicolumn{3}{|c|}{ Continent } & \multicolumn{2}{|c|}{ Sample size } \\
\hline & & & & Europe & America & Africa & $S$ & $\mathrm{~L}$ \\
\hline \multirow[t]{5}{*}{1} & \multirow[t]{5}{*}{ K vs. Q } & OR & 0.90 & 0.94 & 0.82 & 0.92 & 0.78 & 0.90 \\
\hline & & $95 \% \mathrm{Cl}$ & $0.82-1.00$ & $0.89-0.99$ & $0.57-1.17$ & $0.80-1.06$ & $0.61-1.00$ & 0.83-0.99 \\
\hline & & $p$ & 0.014 & 0.019 & 0.276 & 0.264 & 0.053 & 0.033 \\
\hline & & $p_{\mathrm{H}}$ & $<0.001$ & 0.245 & $<0.001$ & 0.230 & 0.560 & $<0.001$ \\
\hline & & $p_{E}$ & 0.152 & 0.048 & 0.353 & 0.090 & $<0.001$ & 0.154 \\
\hline \multirow[t]{5}{*}{2} & \multirow[t]{5}{*}{$K K$ vs. $K Q+Q Q$} & OR & 0.89 & 0.95 & 0.78 & 0.84 & 0.70 & 0.90 \\
\hline & & $95 \% \mathrm{Cl}$ & $0.80-0.98$ & $0.90-1.01$ & $0.50-1.21$ & $0.58-0.94$ & $0.51-0.96$ & $0.81-1.00$ \\
\hline & & $p$ & 0.024 & 0.095 & 0.263 & 0.346 & 0.029 & 0.061 \\
\hline & & $p_{H}$ & $<0.001$ & 0.303 & $<0.001$ & 0.064 & 0.291 & $<0.001$ \\
\hline & & $p_{E}$ & 0.181 & 0.044 & 0.430 & 0.262 & 0.140 & 0.178 \\
\hline \multirow[t]{5}{*}{3} & \multirow[t]{5}{*}{$K Q$ vs. $K K+Q Q$} & OR & 1.10 & 1.02 & 1.29 & 1.14 & 1.37 & 1.08 \\
\hline & & $95 \% \mathrm{Cl}$ & $0.99-1.21$ & $0.96-1.08$ & $0.86-1.94$ & $0.80-1.64$ & $1.01-1.88$ & $0.98-1.19$ \\
\hline & & $p$ & 0.062 & 0.453 & 0.217 & 0.472 & 0.045 & 0.136 \\
\hline & & $p_{\mathrm{H}}$ & $<0.001$ & 0.505 & $<0.001$ & 0.051 & 0.465 & $<0.001$ \\
\hline & & $p_{E}$ & 0.163 & $<0.001$ & 0.391 & 0.258 & $<0.001$ & 0.162 \\
\hline \multirow[t]{5}{*}{4} & \multirow[t]{5}{*}{ Qvs. K } & OR & 1.11 & 1.06 & 1.22 & 1.08 & 1.27 & 1.10 \\
\hline & & $95 \% \mathrm{Cl}$ & $1.02-1.22$ & $1.01-1.12$ & $0.85-1.75$ & $0.94-1.25$ & $1.00-1.63$ & $1.01-1.21$ \\
\hline & & $p$ & 0.014 & 0.019 & 0.276 & 0.264 & 0.053 & 0.033 \\
\hline & & $p_{H}$ & $<0.001$ & 0.245 & $<0.001$ & 0.230 & 0.560 & $<0.001$ \\
\hline & & $p_{E}$ & 0.152 & 0.048 & 0.353 & 0.090 & $<0.001$ & 0.154 \\
\hline \multirow[t]{5}{*}{5} & \multirow[t]{5}{*}{$Q Q$ vs. $K K+K Q$} & OR & 1.14 & 1.29 & 1.07 & 1.03 & 1.12 & 1.14 \\
\hline & & $95 \% \mathrm{Cl}$ & $1.01-1.23$ & $1.08-1.54$ & $0.71-1.60$ & $0.80-1.34$ & $0.63-2.01$ & $1.00-1.29$ \\
\hline & & $p$ & 0.039 & 0.005 & 0.752 & 0.804 & 0.693 & 0.043 \\
\hline & & $p_{H}$ & 0.350 & 0.765 & 0.056 & 0.659 & 0.481 & 0.251 \\
\hline & & $p_{E}$ & 0.085 & $<0.001$ & 0.310 & $<0.001$ & $<0.001$ & 0.120 \\
\hline
\end{tabular}

OR: Odds ratio, Cl: Confidence interval, $p: p$ value based on between-study $Z$ test, $p_{H}: p$ value based on $Q$ test between-study heterogeneity, $p_{\mathrm{E}}$ : $p$ value based on between-study Egger's test, L: Large ( $\geq 400$ samples), S: Small (< 400 samples), T2DM: Type 2 diabetes mellitus

$\mathrm{Q} p=0.276 ; \mathrm{KK}$ vs. KQ+QQ $p=0.263 ; \mathrm{KQ}$ vs. $\mathrm{KK}+\mathrm{QQ} p=0.217$; $\mathrm{Q}$ vs. $\mathrm{K} p=0.276$; QQ vs. $\mathrm{KK}+\mathrm{KQ} p=752$ ), all genetic models of the Africa continent subgroup (K vs. Q $p=0.264 ; \mathrm{KK}$ vs. KQ $+\mathrm{QQ} p=0.346 ; \mathrm{KQ}$ vs. KK + QQp $=0.472 ; \mathrm{Q}$ vs. $\mathrm{K} p=0.264$; $\mathrm{QQ}$ vs. $\mathrm{KK}+\mathrm{KQ} p=804)$, three genetic models of the small sample subgroup (K vs. $\mathrm{Q} p=0.053$; Q vs. $\mathrm{K} p=0.053$; QQ vs. KK $+\mathrm{KQ} p$ $=0.693)$, and two genetic models of the large sample subgroup (KK vs. KQ+QQ $p=0.061 ; \mathrm{KQ}$ vs. $\mathrm{KK}+\mathrm{QQ} p=0.136)$.

\section{Source of heterogeneity}

Evidence for heterogeneity $(p<0.10)$ between studies was found in four genetic models $\left(\mathrm{K} v s\right.$. $\mathrm{Q} p_{\mathrm{H}}<$
$0.001 ; \mathrm{KK}$ vs. $\mathrm{KQ}+\mathrm{QQ} p_{\mathrm{H}}<0.001 ; \mathrm{KQ}$ vs. KK $+\mathrm{QQ} p_{\mathrm{H}}<0.001 ; \mathrm{Q}$ vs. $\left.\mathrm{K} p_{\mathrm{H}}<0.001\right)$ and one genetic model had no heterogeneity (QQ vs. KK + $\left.\mathrm{KQ} p_{\mathrm{H}}=0.350\right)$. Therefore, four genetic models in this study were assessed using random effect model, and one genetic model was assessed using fixed effect model. Summary evidence of heterogeneity regarding the correlation of ENPP1 K121Q gene polymorphism with T2DM is described in Table 2. In the subgroup analysis, evidence for heterogeneity was found in all genetic models of the America continent subgroup (K vs. $\mathrm{Q} p_{\mathrm{H}}<0.001 ; \mathrm{KK}$ vs. KQ+ $\mathrm{QQ} p_{\mathrm{H}}<0.001 ; \mathrm{KQ}$ vs. KK $+\mathrm{QQ} p_{\mathrm{H}}<0.001 ; \mathrm{Q}$ vs. $\mathrm{K} p_{\mathrm{H}}<0.001 ; \mathrm{QQ}$ vs. $\mathrm{KK}+\mathrm{KQ} p_{\mathrm{H}}=0.056$ ), two genetic models of the Africa continent subgroup 
(KK vs. KQ + QQ $p_{\mathrm{H}}=0.064 ; \mathrm{KQ}$ vs. $\mathrm{KK}+\mathrm{QQ}$ $\left.p_{\mathrm{H}}=0.051\right)$, four genetic models of the large sample subgroup (K vs. $\mathrm{Q} p_{\mathrm{H}}<0.001 ; \mathrm{KK}$ vs. $\mathrm{KQ}+\mathrm{QQ} p_{\mathrm{H}}$ $<0.001 ; \mathrm{KQ}$ vs. $\mathrm{KK}+\mathrm{QQ} p_{\mathrm{H}}<0.001 ; \mathrm{Q}$ vs. $\mathrm{K} p_{\mathrm{H}}<$ $0.001)$. Therefore, random effect model was used to calculate OR 95\% CI in these subgroups. While, no evidence for heterogeneity was found in all genetic models of the Europe continent subgroup ( $\mathrm{K}$ vs. $\mathrm{Q} p_{\mathrm{H}}=0.245 ; \mathrm{KK}$ vs. KQ+QQ $p_{\mathrm{H}}=0.303 ; \mathrm{KQ}$ vs. $\mathrm{KK}+\mathrm{QQ} p_{\mathrm{H}}=0.505 ; \mathrm{Q}$ vs. $\mathrm{K} p_{\mathrm{H}}=0.245 ; \mathrm{QQ}$ vs. $\left.\mathrm{KK}+\mathrm{KQ} p_{\mathrm{H}}=0.765\right)$, three genetic models of the Africa continent subgroup (K vs. $\mathrm{Q} p_{\mathrm{H}}=0.230$; $\mathrm{Q}$ vs. $\mathrm{K} p_{\mathrm{H}}=0.230$; $\mathrm{QQ}$ vs. $\left.\mathrm{KK}+\mathrm{KQ} p_{\mathrm{H}}=0.659\right)$, all genetic models of the small sample subgroup (K vs. $\mathrm{Q} p_{\mathrm{H}}=0.560 ; \mathrm{KK}$ vs. KQ+QQ $p_{\mathrm{H}}=0.291 ; \mathrm{KQ}$ vs. $\mathrm{KK}+\mathrm{QQ} p_{\mathrm{H}}=0.465 ; \mathrm{Q}$ vs. $\mathrm{K} p_{\mathrm{H}}=0.560 ; \mathrm{QQ}$ vs. $\left.\mathrm{KK}+\mathrm{KQ} p_{\mathrm{H}}=0.481\right)$, and one genetic model of the large sample size subgroup (QQ vs. $K K+K Q p_{\mathrm{H}}$ $=0.251)$. Therefore, fixed effect model was used to calculate OR 95\% CI in these subgroups.

\section{Potential publication bias}

Using Egger's test, no publication bias was detected (K vs. $\mathrm{Q} p_{\mathrm{E}}=0.152 ; \mathrm{KK}$ vs. KQ+QQ $p_{\mathrm{E}}=0.181$; $\mathrm{KQ}$ vs. $\mathrm{KK}+\mathrm{QQ} p_{\mathrm{E}}=0.163 ; \mathrm{Q}$ vs. $\mathrm{K} p_{\mathrm{E}}=0.152$; $\mathrm{QQ}$ vs. $\left.K K+K Q p_{\mathrm{E}}=0.085\right)$. Summary Egger's test regarding the correlation of ENPP1 K121Q gene polymorphism with T2DM is described in Table 2. In the subgroup analysis, no publication bias was detected in all genetic models of the America continent subgroup ( $\mathrm{K}$ vs. $\mathrm{Q} p_{\mathrm{E}}=0.353$; KK vs. $\mathrm{KQ}+$ $\mathrm{QQ} p_{\mathrm{E}}=0.430 ; \mathrm{KQ}$ vs. KK $+\mathrm{QQ} p_{\mathrm{E}}=0.391 ; \mathrm{Q}$ vs. $\mathrm{K} p_{\mathrm{E}}=0.353$; $\mathrm{QQ}$ vs. $\mathrm{KK}+\mathrm{KQ} p_{\mathrm{E}}=0.310$ ), four genetic models of the Africa continent subgroup ( $\mathrm{K}$ vs. $\mathrm{Q} p_{\mathrm{E}}=0.090$; $\mathrm{KK}$ vs. $\mathrm{KQ}+\mathrm{QQ} p_{\mathrm{E}}=$ 0.262 ; $\mathrm{KQ}$ vs. $\mathrm{KK}+\mathrm{QQ} p_{\mathrm{E}}=0.258 ; \mathrm{Q}$ vs. $\mathrm{K} p_{\mathrm{E}}=$ $0.090)$, one genetic model of the small sample size subgroup (KK vs. KQ + QQ $p_{\mathrm{E}}=0.140$ ), and all genetic models of the large sample size subgroup $(\mathrm{K}$ vs. $\mathrm{Q} p_{\mathrm{E}}=0.154 ; \mathrm{KK}$ vs. $\mathrm{KQ}+\mathrm{QQ} p_{\mathrm{E}}=0.178 ; \mathrm{KQ}$ vs. $\mathrm{KK}+\mathrm{QQ} p_{\mathrm{E}}=0.162 ; \mathrm{Q}$ vs. $\mathrm{K} p_{\mathrm{E}}=0.154 ; \mathrm{QQ}$ vs. $\left.\mathrm{KK}+\mathrm{KQ} p_{\mathrm{E}}=0.120\right)$. On the other hand, publication bias was detected in all genetic models of the Europe continent subgroup (K vs. $\mathrm{Q} p_{\mathrm{E}}=0.048$; $\mathrm{KK}$ vs. KQ+QQ $p_{\mathrm{E}}=0.044 ; \mathrm{KQ}$ vs. $\mathrm{KK}+\mathrm{QQ} p_{\mathrm{E}}$ $<0.001$; $\mathrm{Q}$ vs. $\mathrm{K} p_{\mathrm{E}}=0.048$; QQ vs. $\mathrm{KK}+\mathrm{KQ} p_{\mathrm{E}}$ $<0.001$ ), one genetic model of the Africa continent subgroup (QQ vs. KK $+\mathrm{KQ} p_{\mathrm{E}}<0.001$ ), and four genetic models of the small sample size subgroup (K vs. $\mathrm{Q} p_{\mathrm{E}}<0.001 ; \mathrm{KQ}$ vs. KK+QQ $p_{\mathrm{E}}<0.001 ; \mathrm{Q}$ vs. $\mathrm{K} p_{\mathrm{E}}<0.001 ; \mathrm{QQ}$ vs. $\left.\mathrm{KK}+\mathrm{KQ} p_{\mathrm{E}}<0.001\right)$.

\section{DISCUSSION}

Overexpression of ENPP1 has been implicated in the pathology of a number of diseases, including T2DM. ENPP1 is a transmembrane glycoprotein that inhibits the tyrosine kinase activity of IR and down-regulates insulin signaling in cells (11) through inhibiting the autophosphorylation of IR and impairing insulin signaling downstream of IR (12). A study found that the $121 \mathrm{Q}$ variant has a greater inhibitory action on IR than does the $121 \mathrm{~K}$ variant (13). Because of the effects of ENPP1 on IR signaling, a series of studies have focused on the contribution of polymorphisms within ENPP1 cluster genes to the T2DM risk. However, results have been contradictory. This study reported the association of ENPP1 K121Q gene polymorphism with T2DM risk, although the power of this meta-analysis was limited due to the size and heterogeneity of studies.

The results indicated that the ENPP1 K121Q gene polymorphism was associated with increased (Q vs. $\mathrm{K}, \mathrm{OR} 95 \% \mathrm{CI}=1.11[1.02-1.22], p=0.014$; QQ vs. $\mathrm{KK}+\mathrm{KQ}$, OR 95\% CI = 1.14 [1.01-1.23], $p$ $=0.039)$ and decreased T2DM risk $(\mathrm{K}$ vs. $\mathrm{Q}, \mathrm{OR}$ $95 \% \mathrm{CI}=0.90[0.82-1.00], p=0.014 ; \mathrm{KK}$ vs. $\mathrm{KQ}+\mathrm{QQ}$, OR 95\% CI $=0.89[0.80-0.98], p=$ 0.024). Summary of ORs $95 \%$ CIs, correlation, heterogeneity, and Egger's test regarding the correlation of ENPP1 K121Q gene polymorphism with T2DM is described in Table 2, while study characteristics are described in Table 1. Forest plot regarding the correlation of ENPP1 K121Q gene polymorphism with T2DM is described in Figure 2 for K vs. Q model. Previous similar meta-analysis studies reported the correlation of ENPP1 K121Q gene polymorphism with the risk of T2DM in distinct populations. $\mathrm{Li}$ (34) conducted a meta-analysis study regarding the association of the ENPP1 K121Q gene polymorphism with the risk of T2DM in Chinese population. He found that the ENPP1 K121Q gene polymorphism was in correlation with T2DM susceptibility (OR 95\% CI = 1.29 [1.091.53] $p=0.003)$ and the $\mathrm{Q}$ allele of the ENPP1 
K121Q gene might be the risk factor for T2DM in the Chinese population. Jing et al. (35) conducted a study regarding the association of polymorphisms in five candidate genes with the risk of T2DM in Chinese population. They found that the Q allele of ENPP1 K121Q gene increased the risk of T2DM in Chinese population (OR 95\% CI = 1.41 [1.131.76] $p=0.003)$. However, they did not provide the results of various genetic model analyses. It was probably because of the fact that they analyzed five genes. Therefore, the results of each gene analysis was incomplete. Wang et al. (36) conducted a study regarding the association of ENPP1 K121Q gene polymorphism with the risk of T2DM in Chinese population. They showed that the Q allele of ENPP1 K121Q gene was significantly associated with the risk of T2DM in Chinese population (OR 95\% $\mathrm{CI}=1.50[1.39-1.62] p<0.001)$. However, they only studied the Chinese population, and several references on Chinese population were difficult to find because most of them published their studies in China National Knowledge Infrastructure (CNKI). Ruoqi et al. (37) conducted a study regarding the correlation of ENPP1 K121Q gene polymorphism with the risk of obesity in European population. They showed that the ENPP1 K121Q gene polymorphism correlated with the risk of obesity (OR $95 \% \mathrm{CI}=1.25[1.04-1.52] p=0.021)$. McAteer et al. (38) conducted a study on the association between ENPP1 K121Q gene polymorphism and the risk of T2DM in European population. They showed that the Q allele of ENPP1 K121Q gene increased the risk of T2DM (OR 95\% CI $=1.38$ $[1.10-1.74] p=0.005)$. However, they only studied the European population. Therefore, a study with a larger population scale is required to determine more precise association. Tang et al. (39) conducted a study regarding the association of ENPP1 K121Q gene polymorphism with the risk of T2DM in different populations. They found that the $\mathrm{Q}$ allele of the ENPP1 K121Q gene may contribute to the susceptibility to T2DM in Caucasians and Asians (OR $95 \% \mathrm{CI}=1.29[1.16-1.44] p<0.001)$. However, there were several error calculations. Summary of meta-analysis studies on the association between ENPP1 K121Q gene polymorphism and the risk for T2DM in different areas is described in Table 3. Our study reported the correlation of ENPP1 K121Q gene polymorphism with the risk of T2DM in different populations. Furthermore, in the subgroup analysis, the ENPP1 K121Q gene polymorphism was associated with the risk of T2DM in three genetic models of the Europe continent subgroup (K vs. $\mathrm{Q} p=0.019$; $\mathrm{Q}$ vs. $\mathrm{K} p=0.019$; $\mathrm{QQ}$ vs. KK $+\mathrm{KQ} p=0.005)$, two genetic models of the small sample subgroup (KK vs. KQ + QQ $p=0.029 ; \mathrm{KQ}$ vs. $\mathrm{KK}+\mathrm{QQ} p=0.045)$, and three genetic models of the large sample subgroup ( $\mathrm{K}$ vs. $\mathrm{Q} p=0.033$; $\mathrm{Q}$ vs. $\mathrm{K} p=0.033$; $\mathrm{QQ}$ vs. $\mathrm{KK}+\mathrm{KQ} p=0.043$ ). The ENPP1 K121Q gene polymorphism had no significant association with the risk of T2DM in two genetic models of the Europe continent subgroup (KK vs. KQ + QQ $p=0.095$; KQ vs. KK + $\mathrm{QQ} p=0.453)$, all genetic models of the America continent subgroup (K vs. Q $p=0.276$; KK vs. KQ $+\mathrm{QQ} p=0.263 ; \mathrm{KQ}$ vs. $\mathrm{KK}+\mathrm{QQ} p=0.217$; $\mathrm{Q}$ vs. $\mathrm{K} p=0.276$; $\mathrm{QQ}$ vs. $\mathrm{KK}+\mathrm{KQ} p=752$ ), all genetic models of the Africa continent subgroup (K vs. $\mathrm{Q} p=0.264$; KK vs. $\mathrm{KQ}+\mathrm{QQ} p=0.346 ; \mathrm{KQ}$ vs. $\mathrm{KK}+\mathrm{QQ} p=0.472$; $\mathrm{Q}$ vs. $\mathrm{K} p=0.264$; $\mathrm{QQ}$ vs. $\mathrm{KK}+\mathrm{KQ} p=804)$, three genetic models of the small sample subgroup ( $\mathrm{K}$ vs. $\mathrm{Q} p=0.053$; $\mathrm{Q}$ vs. $\mathrm{K} p=0.053$; QQ vs. $\mathrm{KK}+\mathrm{KQ} p=0.693)$, and two genetic models of the large sample subgroup (KK vs. $\mathrm{KQ}+\mathrm{QQ} p=0.061 ; \mathrm{KQ}$ vs. KK + QQ $p=0.136$ ) However, these results should be interpreted with caution because the relatively small sample size or multiple testing could drive false positive findings.

The results of the study also showed the tendency of the Q allele of ENPP1 K121Q gene to correlate with an increased risk of T2DM, while the $\mathrm{K}$ allele of ENPP1 K121Q gene correlated with a reduced risk of T2DM. The mechanism underlying these results is complex and difficult to explain. However, it is alleged that the mechanism involving ENPP1 and insulin resistance has an important role in the process. Although the primary factors causing T2DM are unknown, it is clear that insulin resistance plays a major role in T2DM development $(40,41)$. The mechanism of insulin resistance is a complex, involving several genes including ENPP1. The role of ENPP1 in T2DM is associated with impaired insulin signaling. ENPP1 binds to IR molecule, thereby inhibiting insulin-induced conformational change (42) that leads to IR autophosphorylation and tyrosine kinase activation $(25,43)$. Inhibition 
TABLE 3. Summary of meta-analysis studies regarding the association between the ENPP1 K121Q gene polymorphism and the risk of T2DM in different areas

\begin{tabular}{|c|c|c|c|c|c|}
\hline Author \& Year & Cases/controls & Population & $\mathrm{OR}[95 \% \mathrm{Cl}]$ & $p$ & Comments \\
\hline McAteer et al. 2008 & $15801 / 26241$ & Europe & $1.38[1.10-1.74]$ & 0.005 & $\begin{array}{l}\text { Only European population, need } \\
\text { larger sample size }\end{array}$ \\
\hline Wang et al. 2010 & $539 / 404$ & China & $1.50[1.39-1.62]$ & 0.001 & $\begin{array}{l}\text { The Chinese references were } \\
\text { difficult to find }\end{array}$ \\
\hline Ruoqi et al. 2011 & $11372 / 12952$ & Europe & $1.25[1.04-1.52]$ & 0.021 & $\begin{array}{l}\text { Only European population, need } \\
\text { larger sample size }\end{array}$ \\
\hline Li 2012 & $6362 / 5493$ & China & $1.29[1.09-1.53]$ & 0.003 & $\begin{array}{l}\text { The Chinese references were } \\
\text { difficult to find }\end{array}$ \\
\hline Jing et al. 2012 & NA & China & $1.41[1.13-1.76]$ & 0.003 & $\begin{array}{l}\text { The Chinese references were } \\
\text { difficult to find }\end{array}$ \\
\hline Tang et al. 2014 & $24348 / 32613$ & Mix & $1.29[1.16-1.44]$ & 0.001 & There were several error calculations \\
\hline Our results & $17717 / 28022$ & $\begin{array}{l}\text { Europe, } \\
\text { America, Africa }\end{array}$ & $1.11[1.02-1.22]$ & 0.014 & \\
\hline
\end{tabular}

OR: Odds ratio, Cl: Confidence interval, $p$ : Significance, NA: Not available

of this conformational change is caused by protein interaction. The change in the exon 4 of ENPP1 gene which leads to a lysine $(\mathrm{K})$ to glutamine $(\mathrm{Q})$ substitution in codon 121 (K121Q) might influence protein-protein interactions. Furthermore, the Q allele of ENPP1 K121Q gene has been shown to influence ENPP1 protein function by inhibiting insulin receptor function and insulin signaling (44). This is because the $121 \mathrm{Q}$ variant binds to IR with higher affinity than the $121 \mathrm{~K}$ variant (25) and is more potent in inhibiting IR autophosphorylation (43). This might explain the results of this study which indicated that the Q allele of ENPP1 K121Q gene correlated with an increased risk of T2DM.

There were several limitations in the meta-analysis. First, this analysis was primarily based on unadjusted effect estimates. Therefore, the potential covariates including age, gender, body mass index, environmental factors such as smoking, and level of blood glucose, which might influence the effect estimates, were not controlled for. Second, the possibility of a false negative remains due to the small size of the studies even when combined. Thus, further studies with larger sample size are required to investigate the associations.

\section{CONCLUSION}

In summary, this meta-analysis suggested that the ENPP1 K121Q gene polymorphism was associated with decreased and increased risk of T2DM in the American, European, and African populations. Further studies considering gene-environment interactions should be conducted to investigate the associations between the ENPP1 K121Q gene polymorphism and the risk of T2DM.

\section{CONFLICT OF INTEREST}

The author declares no conflict of interest.

\section{REFERENCES}

1. Horikawa Y, Oda N, Cox NJ, Li X, Orho-Melander M, Hara M, et al. Genetic variation in the gene encoding calpain-10 is associated with type 2 diabetes mellitus. Nature Genet. 2000;26:163-75.

http://dx.doi.org/10.1038/79876.

2. DeFronzo RA. Pharmacologic therapy for type 2 diabetes mellitus. Annals Internal Med. 1999;131(4):281-304.

http://dx.doi.org/10.7326/0003-4819-131-4-199908170-00008.

3. American Diabetes Association. Diagnosis and classification of diabetes mellitus. Diabetes Care. 2004;27(1):S5-10.

http://dx.doi.org/10.2337/diacare.27.2007.S5

4. Keshavarz P, Inoue H, Sakamoto Y, Kunika K, Tanahashi T, Nakamura N et al. No evidence for association of the ENPP1 (PC-1) K121Q variant with risk of type 2 diabetes in a Japanese population. J Hum Genet. 2006;51(6):559-66.

http://dx.doi.org/10.1007/s10038-006-0399-0.

5. World Health Organization. Global report on diabetes. Geneva: World Health Organization; 2016.

6. Wild S, Roglic G, Green A, Sicree R, King H. Global prevalence of diabetes: Estimates for the year 2000 and projections for 2030. Diabetes Care. 2004;27(5):1047-53.

http://dx.doi.org/10.2337/diacare.27.5.1047.

7. Lyssenko V, Laakso M. Genetic screening for the risk of type 2 diabetes. 
Diabetes Care. 2013;36(2):S120-6.

http://dx.doi.org/10.2337/dcS13-2009.

8. Badaruddoza B, Barna B, Matharoo K, Bhanwer AJS. A case-control association study of K121Q (rs 1044498) and G/T (rs 1225572) variants in ENPP1 and TCF7L2 genes with type 2 diabetes mellitus in north Indian Punjabi population. Int J Diabetes Dev Ctries. 2015;35(4):546-53.

http://dx.doi.org/10.1007/s13410-015-0337-9.

9. Yoon J, Wang H, Kim YC, Yoshimoto M, Abbasi S, Morse HC. Plasma cell alloantigen ENPP1 is expressed by a subset of human B Cells with potential regulatory functions. Immunol Cell Biol. 2016.

http://dx.doi.org/10.1038/icb.2016.31.

10. Pan W, Chandalia M, Abate N. New insights into the role of ENPP1 in insulin resistance. J Metabonomics Metabolites. 2012;1(1):1000e103.

DOI: 10.4172/2325-9736.1000e103.

11. Stolerman ES, Manning AK, McAteer JB, Dupuis J, Fox CS, Cupples LA, et al. Haplotype structure of the ENPP1 gene and nominal association of the $\mathrm{K} 121 \mathrm{Q}$ missense single nucleotide polymorphism with glycemic traits in the Framingham Heart Study. Diabetes. 2008;57(7):1971-7.

http://dx.doi.org/10.2337/db08-0266.

12. Maddux BA, Goldfine ID. Membrane glycoprotein PC-1 inhibition of insulin receptor function occurs via direct interaction with the receptor a-subunit. Diabetes. 2000;49(1):13-9

http://dx.doi.org/10.2337/diabetes.49.1.13.

13. Costanzo BV, Trischitta V, Di Paola R, Spampinato D, Pizzuti A, Vigneri R, et al. The $Q$ allele variant (GLN121) of membrane glycoprotein PC-1 interacts with the insulin receptor and inhibits insulin signaling more effectively than the common K allele variant (LYS121). Diabetes. 2001;50(4):831-6. http://dx.doi.org/10.2337/diabetes.50.4.831

14. Rasmussen SK, Urhammer SA, Pizzuti A, Echwald SM, Ekstrøm CT, Hansen L, et al. The $\mathrm{K} 121 \mathrm{Q}$ variant of the human PC-1 gene is not associated with insulin resistance or type 2 diabetes among Danish Caucasians. Diabetes. 2000;49(9):1608-11.

http://dx.doi.org/10.2337/diabetes.49.9.1608.

15. Abate N, Chandalia M, Satija P, Adams-Huet B, Grundy SM, Sandeep S, et al. ENPP1/PC-1 K121Q polymorphism and genetic susceptibility to type 2 diabetes. Diabetes. 2005;54(4):1207-13

http://dx.doi.org/10.2337/diabetes.54.4.1207.

16. Meyre D, Bouatia-Naji N, Tounian A, Samson C, Lecoeur C, Vatin V, et al. Variants of ENPP1 are associated with childhood and adult obesity and increase the risk of glucose intolerance and type 2 diabetes. Nat Genet. 2005;37(8):863-7.

http://dx.doi.org/10.1038/ng1604.

17. Chandalia M, Grundy SM, Adams-Huet B, Abate N. Ethnic differences in the frequency of ENPP1/PC1 $121 \mathrm{Q}$ genetic variant in the Dallas Heart Study cohort. J Diabetes Complicat. 2007;21(3):143-8.

http://dx.doi.org/10.1016/j.jdiacomp.2006.11.003.

18. Willer CJ, Bonnycastle LL, Conneely KN, Duren WL, Jackson AU, Scott LJ, et al. Screening of 134 single nucleotide polymorphisms (SNPs) previously associated with type 2 diabetes replicates association with 12 SNPs in nine genes. Diabetes. 2007;56(1):256-64

http://dx.doi.org/10.2337/db06-0461.

19. Bouhaha R, Meyre D, Kamoun $H A$, Ennafaa $H$, Vaillant $E$, Sassi $R$, et al. Effect of ENPP1/PC-1-K121Q and PPARg-Pro12Ala polymorphisms on the genetic susceptibility to T2D in the Tunisian population. Diabetes Res Clin Pract. 2008;81(3):278-83

http://dx.doi.org/10.1016/j.diabres.2008.06.004.

20. Leitao CB, Nabinger GB, Krahe AL, Bolson PB, Gerchman F, Friedman R, et al. The role of K121Q ENPP1 polymorphism in diabetes mellitus and its complications. Braz J Med Biological Res. 2008;41(3):229-34.
http://dx.doi.org/10.1590/S0100-879X2006005000202.

21. Pizzuti A, Frittitta L, Argiolas A, Baratta R, Goldfine ID, Bozzali M, et al. A polymorphism (K121Q) of the human glycoprotein PC-1 gene coding region is strongly associated with insulin resistance. Diabetes. 1999;48(9):1881-4.

http://dx.doi.org/10.2337/diabetes.48.9.1881.

22. Gu HF, Almgren P, Lindholm E, Frittitta L, Pizzuti A, Trischitta V, et al. Association between the human glycoprotein PC-1 gene and elevated glucose and insulin levels in a paired-sibling analysis. Diabetes. 2000;49(9):1601-3.

http://dx.doi.org/10.2337/diabetes.49.9.1601.

23. Barroso I, Luan J, Middelberg RPS, Harding A, Franks PW, Jakes RW, et al. Candidate gene association study in type 2 diabetes indicates a role for genes involved in B-cell function as well as insulin action. PloS Biology. 2003;1(1):041-55

http://dx.doi.org/10.1371/journal.pbio.0000020.

24. Kubaszek A, Markkanen A, Eriksson JG, Forsen T, Osmond C, Barker DJP, et al. The association of the $\mathrm{K} 121 \mathrm{Q}$ polymorphism of the plasma cell glycoprotein-1 gene with type 2 diabetes and hypertension depends on size at birth. J Clin Endocrinol Metab. 2004;89(5):2044-7. http://dx.doi. org/10.1210/jc.2003-031350.

25. Bacci S, Ludovico O, Prudente S, Zhang Y, Di Paola R, Mangiacotti D, et al. The K121Q polymorphism of the ENPP1/PC-1 gene is associated with insulin resistance/atherogenic phenotypes, including earlier onset of Type 2 diabetes and myocardial infarction. Diabetes. 2005;54(10):3021-5. http://dx.doi.org/10.2337/diabetes.54.10.3021.

26. Grarup N, Urhammer SA, Ek J, Albrechtsen A, Glümer C, BorchJohnsen K, et al. Studies of the relationship between the ENPP1 K121Q polymorphism and type 2 diabetes, insulin resistance and obesity in 7,333 Danish white subjects. Diabetologia. 2006;49(9):2097-104.

http://dx.doi.org/10.1007/s00125-006-0353-x.

27. Bochenski J, Placha G, Wanic K, Malecki M, Sieradzki J, Warram JH, et al. New polymorphism of ENPP1 (PC-1) is associated with increased risk of type 2 diabetes among obese individuals. Diabetes. 2006;55(9):2626-30. http://dx.doi.org/10.2337/db06-0191.

28. Lyon HN, Florez JC, Bersaglieri T, Saxena R, Winckler W, Almgren P, et al. Common variants in the ENPP1 gene are not reproducibly associated with diabetes or obesity. Diabetes. 2006;55(11):3180-4. http://dx.doi. org/10.2337/db06-0407.

29. Weedon MN, Shields B, Hitman G, Walker M, McCarthy MI, Hattersley AT, et al. No evidence of association of ENPP1 variants with type 2 diabetes or obesity in a study of 8,089 U.K. Caucasians. Diabetes. 2006;55(11):31759. http://dx.doi.org/10.2337/db06-0410.

30. Meyre D, Bouatia-Naji N, Vatin V, Veslot J, Samson C, Tichet J, et al. ENPP1 K121Q polymorphism and obesity, hyperglycaemia and type 2 diabetes in the prospective DESIR Study. Diabetologia. 2007;50(10):2090-6. http://dx.doi.org/10.1007/s00125-007-0787-9.

31. El Achhab Y, Meyre D, Bouatia-Naji N, Berraho M, Deweirder M, Vatin V, et al. Association of the ENPP1 $\mathrm{K} 121 \mathrm{Q}$ polymorphism with type 2 diabetes and obesity in the Moroccan population. Diabetes Metab. 2009;35(1):37-42. http://dx.doi.org/10.1016/j.diabet.2008.06.005.

32. Yako YY, Madubedube JH, Kengne AP, Erasmus RT, Pillay TS, Matsha TE. Contribution of ENPP1, TCF7L2, and FTO polymorphisms to type 2 diabetes in mixed ancestry ethnic population of South Africa. Afri Health Sci. 2015;15(4):1149-60 http://dx.doi.org/10.4314/ahs.v15i4.14

33. Thakkinstian A, D'Este C, Eisman J, Nguyen T, Attia J. Meta-analysis of molecular association studies: Vitamin $D$ receptor gene polymorphisms and BMD as a case study. J Bone Miner Res. 2004;19(3):419-28. http://dx. doi.org/10.1359/JBMR.0301265. 
34. Li YY. ENPP1 K121Q polymorphism and type 2 diabetes mellitus in the Chinese population: A meta-analysis including 11855 subjects. Metabolism. 2012;61(5):625-33.

http://dx.doi.org/10.1016/j.metabol.2011.10.002.

35. Jing $\mathrm{C}$, Xueyao $\mathrm{H}$, Linong J. Meta-analysis of the association studies between five candidate genes and type 2 diabetes in Chinese Han population. Endocrine. 2012;42(2):307-20.

http://dx.doi.org/10.1007/s12020-012-9643-x.

36. Wang M, Peng C, Qu YL, Huang QY. Association and meta-analysis of ENPP1 K121Q with type 2 diabetes in Han Chinese. [Article in Chinese]. Yi Chuan. 2010;32(8):808-16.

http://dx.doi.org/10.3724/SP.J.1005.2010.00808.

37. Ruoqi W, Donghao Z, Bo X, Xiushan G, Ping Z, Bo W, et al. ENPP1/PC-1 gene $\mathrm{K} 121 \mathrm{Q}$ polymorphism is associated with obesity in European adult populations: Evidence from a meta-analysis involving 24324 subjects. Biomed Environ Sci. 2011;24(2):200-6.

DOI: 10.3967/0895-3988.2011.02.015.

38. McAteer JB, Prudente S, Bacci S, Lyon HN, Hirschhorn JN, Trischitta V, et al. The ENPP1 $\mathrm{K} 121 \mathrm{Q}$ polymorphism is associated with type 2 diabetes in European populations: evidence from an updated meta-analysis in 42,042 subjects. Diabetes. 2008;57(4):1125-30.

http://dx.doi.org/10.2337/db07-1336.

39. Tang S, Shen X, Tang H, Wang C, Wei W, Zhang Q, et al. Association of the ENPP1 K121Q polymorphism with susceptibility to type 2 diabetes in different populations: evidence based on 40 studies. Endocrine J. 2014;61(11):1093-103.

http://dx.doi.org/10.1507/endocrj.EJ14-0272.

40. Shulman GI. Cellular mechanisms of insulin resistance. J Clin Invest. 2000;106(2):171-6.

http://dx.doi.org/10.1172/JCl10583.

41. Reaven G. Insulin resistance, type 2 diabetes mellitus, and cardiovascular disease: The end of the beginning. Circulation. 2005;112(20):3030-2.

http://dx.doi.org/10.1161/CIRCULATIONAHA.105.504670.

42. Kato K, Nishimasu H, Okudaira S, Mihara E, Ishitani R, Takagi J, et al. Crystal structure of Enpp1, an extracellular glycoprotein involved in bone mineralization and insulin signaling. PNAS. 2012;109(42):16876-81.

http://dx.doi.org/10.1073/pnas.1208017109.

43. Maddux BA, Chang Y, Accili D, McGuinness OP, Youngren JF, Goldfine ID. Overexpression of the insulin receptor inhibitor PC-1/ENPP1 induces insulin resistance and hyperglycemia. Am J Physiol Endocrinol Metabolism. 2006;290(4):E746-9.

http://dx.doi.org/10.1152/ajpendo.00298.2005.

44. Sortica DA, Buffon MP, Souza BM, Nicoletto BB, Santer A, Assmann TS, et al. Association between the ENPP1 K121Q polymorphism and risk of diabetic kidney disease: A systematic review and meta-analysis. PLOS ONE. 2015;10(3):e0118416.

http://dx.doi.org/10.1371/journal.pone.0118416. 